\title{
RNA-Templated Semiconductor Nanocrystals
}

\author{
Nan Ma, Chad J. Dooley, and Shana O. Kelley* \\ Eugene F. Merkert Chemistry Center, Boston College, Chestnut Hill, Massachusetts 02467
}

\section{Supporting Information}

tRNA synthetic protocol. WT and MT tRNA were prepared by ligation of an oligonucleotide cassette as described in Wittenhagen, L. M.; Kelley, S. O. Nat. Struct. Biol. 2002, 9, 586-590. Plasmids were harvested from XL1-Blue competent cells (Stratagene) and digested with MVa1 (Ambion) to generate the 3' CCA end. The digested DNA was then phenol/chloroform extracted ( $\mathrm{pH} 8$, Sigma), ethanol precipitated and resuspended in distilled $\mathrm{H}_{2} \mathrm{O}$. The DNA was further purified using G-25 columns (Amersham Pharmacia). Transcription reactions were performed using template DNA (200-400 $\mu \mathrm{g} / \mathrm{mL})$, T7 RNA polymerase (overexpressed in E. coli), RNAsin (400 units/mL, Promega), $40 \mathrm{mM}$ Tris- $\mathrm{HCl}$ (pH 8), $10 \mathrm{mM} \mathrm{NaCl}, 2 \mathrm{mM}$ spermidine, $20 \mathrm{mM} \mathrm{MgCl}$, $4 \mathrm{mM}$ NTPs and $5 \mathrm{mM}$ dithiothreitol. Samples were incubated at $37{ }^{\circ} \mathrm{C}$ for $5 \mathrm{~h}$, with the addition of a second aliquot of polyermase after $2 \mathrm{~h}$. The DNA template was then digested with DNase I (60 units $/ \mathrm{mL}$, Takara) for 30 min. RNA products were extracted with 5:1 phenol/chloroform (pH 4.7, Sigma) and ethanol precipitated. Transcription products were further purified by $12 \%$ denaturing PAGE using 0.5X TBE buffer (45 mM Tris base/45 mM boric acid/1mM EDTA) for $4 \mathrm{~h}$. Purified transcripts were recovered by electroelution, and were ethanol precipitated. tRNA was resuspended in diethyl pyrocarbonate (DEPC) treated water. All solutions were prepared with DEPC treated water.

CdS quantum dots synthetic protocol. To synthesize CdS quantum dots, the two RNA transcripts are first annealed by heating at $70^{\circ} \mathrm{C}$ for 5 minutes then immediately chilled on ice for 20 minutes. $\mathrm{CdCl}_{2}$ was then added to the RNA and the solution was incubated at room temperature for 10 minutes. The $\mathrm{Cd}^{2+}$ will bind to the negatively charged RNA phosphate backbone and form a supersaturated microenvironment that can facilitate the nucleation process and avoid 
the formation of bulk CdS. Finally, $\mathrm{Na}_{2} \mathrm{~S}$ is added into the solution followed by intense vortexing for 10 seconds. The RNA nucleotide: $\mathrm{Cd}^{2+}: \mathrm{S}^{2-}$ molar ratio used is $3: 2: 1.666 \mu \mathrm{M}$ RNA bases, $444 \mu \mathrm{M}$ $\mathrm{CdCl}_{2}$ and $222 \mu \mathrm{M} \mathrm{Na} \mathrm{S}_{2}$ are used for the CdS quantum dots synthesis (total volume $100 \mu \mathrm{L}$ ). The synthesis is performed in a $0.5 \mathrm{~mL}$ eppendorf tube, $\mathrm{Na}_{2} \mathrm{~S}$ is injected into the $\mathrm{CdCl}_{2} / \mathrm{RNA}$ solution and then mixed by intense vortex agitation for 10 seconds. All the solutions are treated with DEPC. Absorbance at $260 \mathrm{~nm}$ was used to quantify the concentration of RNA in solution. Values were obtained by applying an extinction coefficient of $840,000 \mathrm{M}^{-1} \mathrm{~cm}^{-1}$ (WT tRNA) and 952,800 M $\mathrm{cm}^{-1}$ (MT tRNA).

Transmission electron microscopy. High resolution electron micrographs of the prepared nanocrystals were aquired on a JEOL 2010F transmission electron microscope operating at 200 $\mathrm{kV}$. Samples were desalted twice by diluting with $\mathrm{H} 2 \mathrm{O}(1: 10)$ and then concentrating to initial volume via Amicon Ultra Centrifugal Filter Devices (10,000 MWCO). A drop (1_L) of the nanoparticle solution was dispensed onto a $3 \mathrm{~mm}$ copper grid covered with a continuous carbon film. The samples were vacuum dried at room temperature.

Gel filtration chromatography. Gel filtration chromatography was run using a Superose 10/300GL column (Amersham). The flow rate was fixed at $0.35 \mathrm{~mL} / \mathrm{min}$ (11bar), each sample ran an overall time of 80 minutes. The wavelength used to monitor quantum dots was set at $370 \mathrm{~nm}$ and recorded by HP 1100 HPLC system. 0.1 M PBS ( $\mathrm{pH} 7.4$ ) was used as running buffer. 

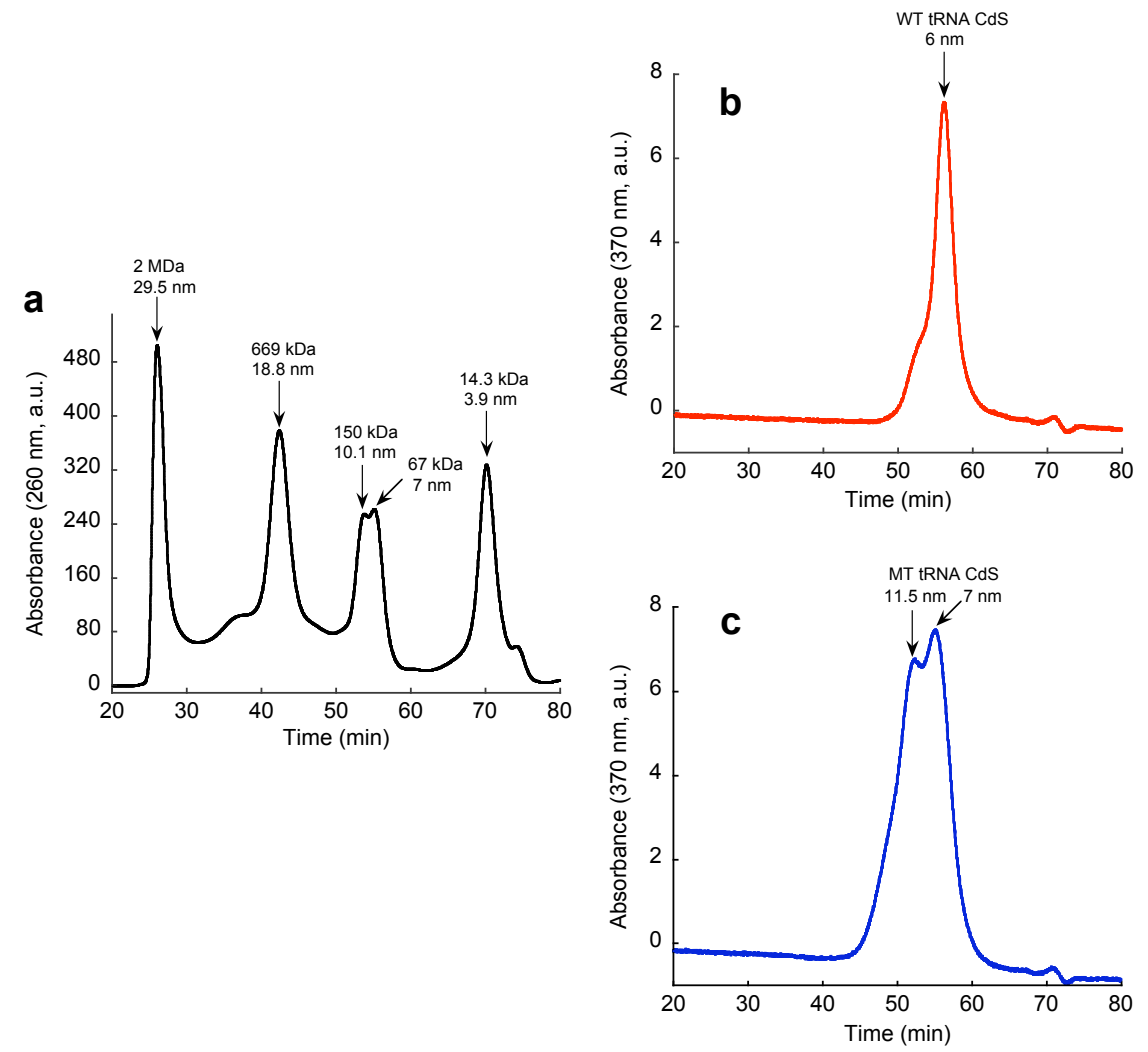

Figure S1. Gel-filtration chromatography of (a) protein standards; (b) WT tRNA-CdS $\left(\lambda_{\text {abs }}=370\right.$ $\mathrm{nm})$; (c) MT E. coli tRNA ${ }^{\text {Leu }}$-CdS $\left(\lambda_{\text {abs }}=370 \mathrm{~nm}\right)$. Samples containing only tRNA did not exhibit any absorbance at $370 \mathrm{~nm}$. Protein standards $\left(\lambda_{\mathrm{abs}}=260 \mathrm{~nm}\right)$ included Blue Dextran (2 MDa), Thyroglobulin (669 kDa), Alcohol Dehydrogenase (150 kDa), Albumin (67 kDa) and Lysozyme $(14.3 \mathrm{kDa})$. 